\title{
Correction To: Free sequences and the tightness of pseudoradial spaces
}

\section{Santi Spadaro ${ }^{1}$}

Published online: 1 April 2021

(c) The Royal Academy of Sciences, Madrid 2021

\section{Correction To: RACSAM (2020) 114:130 https://doi.org/10.1007/s13398-020-00861-z}

In the proof of Theorem 9 it is tacitly assumed that $p$ is not in the closure of $S_{x}$, whenever $x \neq p$. This is not necessarily true, but it can be arranged because the space is Hausdorff. To correct the proof, just insert the following line after the period on Page 5, Line 9: Moreover, if $x \neq p$ we can assume that $p \notin \overline{S_{x}}$.

Publisher's Note Springer Nature remains neutral with regard to jurisdictional claims in published maps and institutional affiliations.

The original article can be found online at https://doi.org/10.1007/s13398-020-00861-z.

\section{Santi Spadaro}

santidspadaro@gmail.com

1 Dipartimento di Ingegneria, Università degli Studi di Palermo, Viale delle Scienze, Ed. 8, 90128 Palermo, Italy 